\title{
Chicago Pragmatism and the Extended Mind Theory
}

Mead and Dewey on the Nature of Cognition

\section{Roman Madzia}

\section{(2) OpenEdition}

\section{Journals}

Electronic version

URL: http://journals.openedition.org/ejpap/609

DOI: 10.4000/ejpap.609

ISSN: 2036-4091

\section{Publisher}

Associazione Pragma

Electronic reference

Roman Madzia, «Chicago Pragmatism and the Extended Mind Theory », European Journal of

Pragmatism and American Philosophy [Online], V-1 | 2013, Online since 16 July 2013, connection on 19 April 2019. URL : http://journals.openedition.org/ejpap/609 ; DOI : 10.4000/ejpap.609

This text was automatically generated on 19 April 2019.

\section{cc) $(1) \ominus$}

Author retains copyright and grants the European Journal of Pragmatism and American Philosophy right of first publication with the work simultaneously licensed under a Creative Commons AttributionNonCommercial-NoDerivatives 4.0 International License. 


\title{
Chicago Pragmatism and the Extended Mind Theory
}

Mead and Dewey on the Nature of Cognition

\author{
Roman Madzia
}

\section{Introduction}

1 In his recent book The Pragmatic Turn, Richard J. Bernstein writes that a philosopher comes alive and speaks to us from the past when his work becomes a fertile source for dealing with current philosophical problems, when his work can be engaged in novel ways. In what is to follow, I would like focus on the question of how the philosophy of pragmatism can possibly contribute to current discussions concerning the nature of cognition instigated by recent findings in cognitive science. I will also try to show that, in many respects, contemporary cognitive neuroscience has been arriving at conclusions reached long ago by two representatives of the Chicago school of pragmatism - George $\mathrm{H}$. Mead and John Dewey. At the same time, I will attempt to view their work through the prism of these new findings. The way I am going to proceed in this paper will be the following: First, I am going to examine the methodological starting points of these two thinkers in their inquiries into the nature of cognition. On the background of these, I am going to take a closer look at some pragmatic ramifications of recent research in particular areas of cognitive neuroscience. Second, elaborating on Mead's theory of the act (with its four stages - impulse, perception, manipulation, and consummation) I will point to numerous striking similarities between the pragmatists' treatment of the notion of cognition and ideas recently suggested by defenders of the extended mind theory. As a point of transition between the first and the second step, I am going to present an argument in favor of a possible pragmatic redefinition of the notion of representation, originally formulated by one of the advocates of the extended mind theory. 


\section{Cognition As An Organic Unity - Dewey's Criticism of The Reflex Arc Concept}

2 Where specifically does cognition stop and action begin? Traditionally, philosophers (and to date also the majority of cognitive scientists) have tended to think of the relation between perception, action, and cognition in terms of what Susan Hurley once dubbed the "classical sandwich" paradigm. In her words, "this conception of the mind, widespread across philosophy and empirical sciences of the mind, regards perception as input from world to mind, action as output from mind to world, and cognition as sandwiched between" (Hurley 2008: 2). In this methodological view, cognition is considered some sort of a central process, taking place in our skulls, which transforms and processes perceptual inputs caused by the contingencies of our environmental surroundings. Action, on the other hand, is usually viewed as some sort of a "servant" to the central cognitive processes, that is, as their mere bodily-instrumental output. At a certain level of analysis the problem of the relation between perception and action can be defined as a problem of the relation between stimulus and response. The main contention of psychological research in Dewey's time was that, if we are to explain what cognition is, we first have to give an account of the process by which perceptual inputs are transformed into motor action. Everything that happens in between can be called cognition. Hence, in order to explain the nature of the central process, we have to examine how the peripheral processes are transformed into one another. However reasonable such a position may seem, Dewey's seminal 1896 paper The Reflex Arc Concept in Psychology ${ }^{1}$ considers such an outlook on the nature of cognition to be deeply misleading. ${ }^{2}$ In this paper Dewey executes a thoroughgoing critique of psychological methodologies that have found their goal in the program of establishing causal and nomological relations between stimuli and responses. Within this view, perceptual stimuli are taken to be independent sensory particulars which trigger in the organism cognitive processes that eventually lead to a motor discharge as a consequence of this processing. The crucial problem with such a heuristic approach is that it tends to apprehend external stimuli, internal processing, and external response as ontologically independent entities, clearly delimited from one another. Under this analysis, Dewey writes:

The sensory stimulus is one thing, the central activity, standing for the idea, and the motor discharge, standing for the act proper, is a third. As a result, the reflex arc is not a comprehensive, or organic unity, but a patchwork of disjointed parts, a mechanical conjunction of unallied processes. (EW 5: 97)

Drawing upon an example of a child seeing a candle introduced first by James in the second chapter of his Psychology, Dewey illustrates the practical working of the reflex arc mechanism. The situation is that of a small child that, after seeing a burning candle in her vicinity for the first time, reaches out to its flame and gets burned. The ordinary interpretation of that situation from the viewpoint of the reflex arc theory would hold that the sensory datum of a light serves as a stimulus to the child, leading eventually to the execution of a motor response in the form of trying to grasp the flame. The resulting burn is, subsequently, a stimulus to withdrawing the hand and so on. Dewey argues that the basic defect of such a theory is the idea of the possibility of dividing the unity of human action into ontologically and temporally separated units. In other words, Dewey's main dissatisfaction with the clas- sical construal of the reflex arc concept lies in the fact that it has misdirected the attention of psychologists from the real issue of trying to 
understand the phenomenon of human action to an exclusive focus upon the parts or stages of the action (cf. Campbell 1995: 34). Whenever we try to divide experience or action into ontologically distinct pieces, we find ourselves unable to put them back together again. The traditional reflex arc concept, thus, has to be replaced by a new heuristic approach in which the stimulus, central reaction, and motor response are taken merely as functional moments of larger organic unity of action:

Upon analysis, we find that we begin not with a sensory stimulus, but with a sensori-motor co-ordination, the optical-ocular, and that in a certain sense it is the movement which is primary, and the sensation which is secondary, the movement of body, head and eye muscles determining the quality of what is experienced. In other words, the real beginning is with the act of seeing; it is looking, and not a sensation of light. The sensory quale gives the value of the act, just as the movement furnishes its mechanism and control, but both sensation and movement lie inside, not outside the act. (EW 5: 97)

What Dewey urges us to do here is to shift our focus from seeing the child as a simple stimulus-response mechanism to an embodied creature situated in an environment, trying to achieve specific goals. That is why in order to understand human action we have to start with "larger co-ordination" of the live creature engaging in purposeful action and interacting with its environment. In such a picture, Dewey holds "the act is seeing no less than before, but it is now seeing-for-reaching purposes. There is still a sensori-motor circuit, one with more content or value" (EW 5: 98). As Leszek Koczanowicz has observed, the act of coordination is for Dewey the only psychological reality (cf. Koczanowicz 1990: 49). The new methodological approach in psychology, proposed by Dewey, enabled not only him, but more importantly Mead, to introduce into psychology the notion of action as a unit of inquiry. Conscious action always starts as a goal-directed activity that engages the whole organism. What should be emphasized at this point is that in Dewey's view the action-goals are present in the acts from their very beginning; and they fulfill there at least two crucial roles. They are, first, instigators of action and, second, regulatory elements directing sensori-motor capacities of the organism towards successful completion of the act. Initially, the child sees the candle as a plaything which leads her to reach out to its flame. The sensory stimulus of the candle, however, not only serves as an initial element or cause of action, but also plays an important role during the motor act of reaching itself as it regulates the movement of the hand, etc. On the flipside, the movement of the child may modify the sensory stimuli coming to her perceptual apparatus: "the sole meaning of the intervening movement is to maintain, reinforce or transform (as the case may be) the original quale" (EW 5: 99). As simple a process as the one of reaching out to a candle may seem, in Dewey's view it cannot be depicted as a mere stimulus-processing-response chain. Rather, it in- volves quite a sophisticated mechanism of creating what Andy Clark calls "action-perception loops" (e.g. Clark 2008: 71, 74-75). In other words, according to Dewey, in the process of cognition, perception is not separable from action for it controls the process of action as a goal-directed behavior from the very beginning until its successful completion. By the same token, action, i. e. its motor component, oftentimes transforms the character of perceptual experience.

Through motion the active organism continuously affects the character of its perceptual experience, just as the character of perceptual experience affects the ways in which the organism moves. In the process of cognition, therefore, the organism and the world enter into what Clark calls continuous reciprocal causation, which occurs when some system is both continuously affecting and simultaneously being affected by activity in some other 
system (cf. Clark 2008: 24). ${ }^{3}$ Cognition, Dewey holds, is a goal-directed activity of a physically embodied and environmentally embedded creature. At the most basic level, cognition is not inherently contentful or intentional (in the classical Brentano's sense), rather the process of life as such, if we interpret it as a process of continuous organic adjustment, is a process of cognition. In this fundamental conviction, the Chicago pragmatists anticipated contemporary systems theory as represented, for instance, in the work of Humberto Maturana: "Living systems are cognitive systems and living as a process is a process of cognition. This statement is correct for all organisms, with or without nervous system" (Maturana \& Varela 1980: 13). The division of the continuum of human perception and action into stimuli and responses is, therefore, an artificial one. In this regard, Joas remarks: "according to Dewey, unless we make an anticipatory judgment about the action in which stimuli and responses are joined together, we can speak only of a temporal succession and not of the causal relation implied by the stimulus-response model" (Joas 1985: 66). From the methodological point of view, Dewey's pragmatic understanding of action as a value-laden and goal-directed activity ${ }^{4}$ necessarily precedes its subsequent functional division into stimuli and responses (cf. EW 5: 96-105). The child perceptually detects the flame in the first place because she sees it as something to be played with, which is why she executes a series of more or less skillful bodily movements to change the character of the experienced candle from being merely present into being available.

6 What does this mean from the perspective of inquiry into the nature of action? I am convinced that there are at least two crucial points to be drawn from the naturalistic accounts of cognition of the Chicago pragmatists. First and foremost, as Kilpinen recently remarked, in pragmatism "action is a universal phenomenon which in itself begs no explanation but rather makes the starting point for explanations"5 (Kilpinen 2008: 1). Secondly, in light of this strictly naturalistic approach to cognition we cannot consistently try to explain it solely in terms of what is going on in our heads. In contrast to mainstream philosophy of mind, pragmatists do not take the mind or its capacity for cognition as self-contained puzzles but rather as phenomena which evolved to "make things happen" (Clark 1997a: 1), to guide action and enable more effective coping with the environment. In short, the brain is an organ for controlling the biological body, rather than a disembodied logical reasoning device. In pragmatism, the explanation of action thus both genealogically and heuristically precedes the explanation of mind and high-order cognitive processes.

7 In Deweyan perspective, the basic characteristics of experience understood in terms of skillful attunement to the world and its implicit practical understanding have to be taken into consideration if we want to analyze the child's action. ${ }^{6}$ As Alva Noë once put it: "perception is not something that happens to us or in us. It is something we do" (Noë 2004: 1). Action and perception are two sides of the same coin, they are the means of our exploratory dynamic engagement with the environment. If cognition is the kind of thing that can be localized anywhere, according to Chicago pragmatists it cannot be situated exclusively in our heads (cf. Mead 1934/1967: 112). In the same manner as Dewey and Mead in the past, Clark currently maintains that "the actual local operations that realize certain forms of human cognizing include inextricable tangles of feedback, feedforward, and feed-around loops: loops that promiscuously criss-cross the boundaries of brain, body, and world. The local mechanisms of mind, if this is correct, are not all in the head. Cognition leaks out into body and world" (Clark 2008: xxviii). 


\section{Cognition and Action Overlapped - The Pragmatic Significance of Attitudes}

8 In his theory of the act, Mead's main concern is to provide a fully naturalistic explanation of cognition that revolves around these fundamental principles. In contrast to classical Watsonian ${ }^{7}$ behaviorism Mead's social behaviorism holds that it is not necessary to explain away consciousness altogether as long as we do not treat it in Cartesian terms as an inner experiential space accessible solely from the first-person perspective:

Watson apparently assumes that to deny the existence of mind or consciousness as a psychical stuff, substance, or entity is to deny its existence altogether, and that a naturalistic or behavioristic account of it as such is out of the question. But, on the contrary, we may deny its existence as a psychical entity without denying its existence in some other sense at all; and if we then conceive it functionally, and as a natural rather than a transcendental phenomenon, it becomes possible to deal with it in behavioristic terms. In short, it is not possible to deny the existence of mind or consciousness or mental phenomena, nor is it desirable to do so. (Mead 1934/1967: 10)

9 Mead, thus, does not see a problem in postulating an inner domain of experience as long as we ascribe it only with proper functional, but not ontological, status. What proper functional status means, in this regard, is that in order to explain action we can postulate existence of neural events in the central nervous system which sensitize the perceiving organism to certain kind of perceptual stimuli and enable it to act toward them. Mead calls these neural paths attitudes, and defines them as non-propositional and sub-personal beginnings of acts in terms of specific readiness of an organism to perform all sorts of responses towards perceptual objects. They are inner, however, "not in the sense of being in another world, a subjective world, but in the sense of being within the organism" (Mead 1934/1967: 5). Attitudes are an integral part of the act although they are not subject to direct observation: "The external act that we observe is a part of the process which has started from within" (Mead 1934/1967: 5). A skeptic might ask whether this sort of treatment does not commit us, again, to exactly the same kind of mind-first explanation against which pragmatism argues. As serious a concern as it may seem at first glance, if we recall Dewey's 1896 article it becomes clear that attitudes are not in any way to be equated with reflective mental states. Attitudes come into existence in higherorder organisms endowed with central nervous systems. On the basis of the organism's active behavior and problem solving, attitudes come into existence as neural pathways encoding bodily habits which are responding to certain kinds of environmental stimulation. For Mead, the very concept or idea of an object is to be equated with "such an organization of a great group of nervous elements as will lead to conduct with reference to the objects about us" (Mead 1934/1967: 70-71). ${ }^{8}$

In his treatment of attitudes, Mead strictly preserves the conceptual and methodological pattern laid out by Dewey in The Reflex Arc Concept. Following Dewey, Mead takes the relation between stages of the act as being not primarily causal but rather functional. Functionality, for that matter, presupposes purposiveness. In words of W. Teed Rockwell: "For Dewey [...] all experience is constituted by its relationship to the world and the goals of the experiencer" (Rockwell 2005: 88). In Mead's theory of the act, this strand of thought is elaborated in his notion of natural teleology of attitudes. In other words, 
attitudes play a pivotal role within the act as purposive, goal-directed elements that control certain course of action from the beginning until the very end.

11 Mead's concept of teleology of attitudes built upon Dewey's model of organic action is currently gaining in credibility due to the recent extensive research into mirror neurons. ${ }^{9}$ These neurons were accidentally discovered by a group of Italian neuroscientists led by Giacomo Rizzolatti during their research into the ventral premotor cortex in primates which is responsible for grasping and manipulating objects. Rizzolatti's group noticed that certain groups of neurons fired not only when a primate was executing a certain motor action but, surprisingly, also when one primate was merely watching another primate (including humans) doing the same thing..$^{10}$ What is important for our discussion here is that mirror neurons are not a new kind of neurons. What Rizzolatti and his colleagues have found, to their own surprise, is that the mirror function is played by the neurons responsible for sensorimotor operations. Referring explicitly to Mead, Rizzolatti and Sinigaglia claim that:

'We look because we handle, and we are able to handle because we look', are the words used almost a century ago by George Herbert Mead to emphasize how perception would not be possible 'without a continued control of such an organ as that of vision by such an organ as that of the hand, and vice versa' [Mead 1907: 388]. Without this mutual control we would not be able to pick up our cup of coffee. However the analysis of the visuo-motor transformations operated by the AIP-FS neurons indicates that the seeing which guides the hand is also (and above all) seeing with the hand, by which the object is immediately coded as a given set of invitations to act. (Rizzolatti \& Sinigaglia 2008: 50)

12 The relevance of the pragmatic concept of action represented by Dewey and Mead for contemporary cognitive neuroscience cannot be clearer. The findings of Rizzolatti and Sinigaglia confirm on empirical grounds not only the very intimate connection between perception and action, but also the goal-directed nature of action in certain higher-order organisms. ${ }^{11}$ Moreover, findings in mirror neuron research also seem to indicate the existence of attitudes. Analogically to Mead's example of grasping a hammer, Rizzolatti and Sinigaglia provide their own example with grasping a cup of coffee:

[w]e will grasp it in different ways depending on whether we are picking it up to drink from it, to rinse it, or simply to move it from one place to another. Moreover, our grip on the cup varies according to the circumstances, whether we are afraid of burning our fingers, or the cup is surrounded by other objects; it will also be influenced by our customs, habits, and our inclination to adhere to certain social rules and so on. (Rizzolatti \& Sinigaglia 2008: 36-37)

13 The present conclusions seem to indicate that Dewey and Mead were right in maintaining that the simple stimulus-response model of action that is still being advocated (in however refined a formulation), is simply inaccurate as a paradigm for explaining the nature of action in higher-order organisms. The one-dimensional model of having a perceptual stimulus of a cup of coffee $\rightarrow$ reaching for it $\rightarrow$ grasping it, etc., is incorrect because in the course of action all these elements work in parallel, the arm moves towards the cup and contemporaneously the hand already assumes the shape necessary for grasping it. If we now recall that, in Mead's view, the concept of object is to be defined in terms of an organization of neural paths that will lead us to certain kinds of conduct with reference to certain perceptual stimuli, we can see why he calls distant perceptual objects as "invitations to conduct" (Mead 1938: 280). In Mead's words: "Man lives in the world of Meaning. What he sees and hears means what he will or might handle" (Mead 1926/1964: 294). 
but rather as cognitive agents, situated in environments where they pursue their practical goals on the basis of what James J. Gibson called affordances. According to Gibson: "affordances of the environment are what it offers the animal, what it provides or furnishes, either for good or ill [...] I mean by it something that refers to both the environment and the animal in a way that no existing term does. It implies the complementarity of the animal and the environment" (Gibson 1979: 127). In this respect, comparative psychologist Louise Barrett makes an insightful point: "Affordances are 'organism-dependent' [...] because they reflect the degree to which an animal with a particular kind of nervous system can detect and make use of particular kinds of environmental opportunities" (Barrett 2011: 98). Similarly, Mark Johnson remarks that the whole process of perceiving affordances and subsequent concept formation "is loosely goal-directed and has always a built-in teleological aspect, since organisms have implicit values they are trying to realize [...], protecting themselves from harm, reproducing, and, in more advanced cases, actualizing their potentialities for growth and fulfillment" (Johnson 2007: 159).

\section{Representation Through Action}

15 From the point of view of the argument I am endorsing here, Mead's crucial concept of attitudes elaborated in light of Dewey's abovementioned 1896 article enables us to redefine the notion of representation on pragmatic grounds. As we have seen, attitudes are outcomes of adaptive strategies of higher-order organisms. These attitudes take the form of neural pathways ${ }^{12}$ enabling them to accurately respond to certain perceptual stimuli in the course of their goal-directed action. Attitudes, therefore, are adaptive neural elements that provide for effective coupling between an organism and its environment. They enable the organism to trigger adequate habitual responses in the presence of the stimuli that may lead them to fulfillment of their pragmatic goals. From the pragmatic point of view, the radical situatedness of the organism in its environment results in the need for creating certain strategies that enable the organism to develop close and cost-effective ways of coupling with it.

16 Attitudes, manifesting themselves in the human action in the form of habits ${ }^{13}$ are, I maintain, examples of exactly this kind strategy. Such a notion of the nature of attitudes (habits) has, in my view, extremely important ramifications for the classical notion of representation. If, on the one hand, there is no ontological gap between an organism and the environment and, on the other, attitudes and habits are formed as the cognitive agent's action-maps of the environment itself, then we no longer have to think of representations in terms of creating models of the external reality. Rather, we should understand them as models of interaction with it. Cognitive agents, thus, do not have to create rich inner models of the world, instead they can "use the world as its own model" (Brooks 1991: 1). Such a view of representation as creating models of interaction resonates also with Charles S. Peirce's words: "we have direct experience of things in themselves. Nothing can be more completely false than that we can experience only our own ideas" (CP 6.95). According to the pragmatists, mind and nature are ultimately the same thing, which means that in the process of cognition the mind engages the environmental structures and reaches out into the world: "We can approach the noumenal nature of reality only through the noumenal nature of thought [...] the

European Journal of Pragmatism and American Philosophy, V-1 | 2013 
experience in which human beings are involved, is the constituent part of reality which they judge" (Mead 1929/1964: 339). In a similar vein, Rockwell points out that "there is no need to make a copy of the world inside the head in order for us to be aware of our environment if our consciousness is partly embodied by the environment itself" (Rockwell 2005: 86). If cognition functions within the brain-body-world nexus, the problem of how our quasi-inner-representations match up with the world does not even come up.

17 I propose, following the distinction introduced by Mark Rowlands, that the kind of human action that executes attitudes and habits in our practical engagements with the world could also be called - deeds (cf. Rowlands 2006: 95). According to Rowlands, deeds occupy the logical space between what he calls actions (which are intentional courses of action perceived and carried out on the personal level of consciousness) and doings (nonintentional movements, of which we are not aware and which serve no purpose connected with action).${ }^{14}$ From the pragmatic point of view, deeds could be defined as individual instances of habits. To use Rowlands' example, deeds include such things as the positioning of fingers in catching a ball that is flying toward us, or the movement of our fingers while playing the piano. They work at sub-personal level of consciousness and as models of interaction with the environmental structures they attune us to the world. Deeds are pre intentional acts - we usually do not think about them in the execution of our everyday tasks, and yet, as expressions of attitudes and habits they effectively map appropriate worldly structures and enable us to achieve our pragmatic goals. We employ them in accurate positioning of our legs when walking the stairs, spontaneous motor operations when driving a car etc. With Michael Wheeler, we can call deeds "actionoriented representations" (Wheeler 2005: 197). Deeds re-present the existing world not as an internal image but as a virtual space of action. What is represented by means of deeds is not knowledge that the environment is so and so, but knowledge of how to negotiate the environment. In the action-oriented approach, says Wheeler, "how the world is is itself encoded in terms of possibilities for action" (Wheeler 2005: 197, original italics). According to pragmatists, mind and nature are, ultimately, the same thing, which means that in the process of cognition the mind engages the environmental structures and reaches out into the world. To paraphrase James' example, deeds represent the appropriate worldly structures in a similar way as the shape of a key matches with a particular lock. Neither the lock, nor the key, can by themselves open the door; they can do it only in conjunction with one another. Following Dewey, representation is, thus, not primarily a noun. Rather, we should understand it first and foremost as a verb. By means of deeds we off-load our cognitive burden partly onto the permanent bodily and environmental structures on which we can rely and achieve our practical goals (cf. Noë 2009: 97-104). ${ }^{15}$

As Rowlands also shows, the concept of deeds is able to satisfy the analytic criteria commonly regarded as sufficient for an item to qualify as representational. There are, it is generally accepted, five such criteria (for a more detailed account cf. Rowlands 2006: 114):

1. Informational condition ${ }^{16}$ - an item $r$ qualifies as a representational item only if it carries information about some state of affairs $s$ that is extrinsic to it.

2. Teleological condition - an item $r$ qualifies as representational only if it has the proper function either of tracking the feature or state of affairs $s$ that produces it, or of enabling an organism to achieve some goal in virtue of tracking $s$.

3. Decouplability condition - item $r$ qualifies as representing state of affairs $s$ only if $r$ is, in an appropriate sense, decouplable from $s$. 
4. Misrepresentation condition - item $r$ qualifies as representing state of affairs $s$ only if it is capable of misrepresenting $s$.

5. Combinatorial condition - for an item $r$ to qualify as representational, it must occur not in isolation but only as part of a more general representational framework.

it is precisely the above-mentioned one. If we should illustrate what such a representation through action looks like in practice, let us imagine the following scenario. I enter a dark room, and in order to be able to see I hit the switch of the lights. If the lights go on, then we can determine whether the deed of hitting the switch counts as representational of certain features of my environment on the basis of the above-listed conditions. The deed of hitting the switch counts as representational because, under the informational condition it, e.g. tracks the location, shape and size of the switch. The deed is teleological because it has the proper function of achieving a practical goal in virtue of tracking the environmental state of affairs $\mathrm{s}$. The deed is also decouplable from the state of affairs it tracks because I can later remember and demonstrate how I hit the switch replicating the same act. Obviously, in the process of representation through action, I can also misrepresent my environment in many ways. Eventually, the deed in question can be combined into a more general representational structure (by means of hitting the switch I try to pursue some further goals - finding a book etc.). It could, therefore, be maintained that attitudes and habits, in the form of deeds represent the appropriate environmental structures if we can achieve particular goals by means of enacting the habits in our action; simply put - deeds represent if we can get things done using them. Successful employment of deeds in the world means that they are correct representations of the appropriate environmental structures since they stand the test of practical action. This is not to say that they represent the world in terms of accurate copying it, but rather in terms of accurate coping with it. ${ }^{17}$

An obvious argument against such a view would be, whether we, in fact, need such a notion of representation. Would it not be better, after all, to get rid of the notion of representation altogether, since its definition given above strays much too far from what we usually take representation to mean? In my opinion, it would not. Successfully employed habits and attitudes tell us something important about the world - they inform us that we can rely on it and, thus, make it available to us. They enable us to be at home in the world by making it transparent, in other words - they re-present it. ${ }^{18}$ It should be noted, however, that such a process representation through action unfolds on a nonpropositional, non-intentional, and sub-personal level of consciousness and should not be understood as a process of matching "inner pictures" in our heads (mental content) with the world "out there." Representation, in the pragmatist rendition, is thoughtless. That is to say, it is a bodily process of enacting the world by means of our habits (deeds) and, for most of the time, does not need to be mediated by mental content.

21

Since our minds are a genuine part of nature, they do not have to copy the world in its entirety. In fact, they are not even able to do so. As Noë convincingly shows, our memory is rather weak in storing detailed information about the surrounding environment (cf. e.g. Noë 2004; 2012). This fact, however, makes very good sense from the evolutionary point of view. It would be energetically as well as computationally extremely costly (and consequently disadvantageous) for any organism to create and store inner representations of environmental structures. An organism with this kind of cognitive strategy would be at a great disadvantage in comparison to an organism which had 
merely developed effective strategies for detecting necessary environmental information when needed. In this respect, Clark writes: "In general, evolved creatures will neither store nor process information in costly ways when they can use the structure of the environment and their operations upon it as a convenient stand-in for the informationprocessing operations concerned. That is, know only as much as you need to know to get the job done" (Clark 1997a: 46). If this heuristic picture, vividly dubbed by Clark the "007 Principle," is correct, i.e., if it is true that cognition has evolved in order to work in such close conjunction with environmental structures appropriate for reaching the cognitive agent's goals, then cognition is realized not only by internal neural mechanisms but also by the world itself. In this regard, Mead remarks: "[c]onsciousness is functional, not substantive; and in either of the main senses of the term it must be located in the objective world rather than in the brain" (Mead 1934/1967: 112). By the same token, if organisms enact certain environmental structures in the course of their problem-solving activities, these structures become in a way their cognitive architecture. In other words, we can reasonably say that organisms are not passive recipients of the environmental pressures but on the contrary, they are active "managers" (or "engineers") in constructing their cognitive niches, which can be, following Clark, defined as an outcome of "the process by which animals build physical structures that transform problem spaces in ways that aid (or sometimes impede) thinking and reasoning about some target domain or domains" (Clark 2008: 62). ${ }^{19}$ Cognitive niches, then, are used by organisms as environmental structures for off-loading some of the practical and cognitive burdens of their actions directly onto the world. However, as Rowlands points out, "division of epistemic burden requires division of epistemic credit" (Rowlands 2003: 179). Representation, we can therefore contend, does not take place exclusively in our heads, as classical epistemologists would hold, but, at least in part, also in the world itself by being enacted in our action.

\section{Mind and Body Extended - Mead's Theory of the Act}

The concept of cognition and representation as processes taking place, at least partly, in the world makes an important case for a pragmatic defense of realism. Too often pragmatism has been accused of being a subjectivist philosophy which denies the existence of objective facts independent of our mind. In light of what we have considered so far, ho wever, it becomes clear that the pragmatist theory of knowledge actually opposes such views. An illustrative example of this is Mead's theory of the act. In the remainder of this paper, I would, therefore, like to analyze how the above-mentioned conceptual foundations are embodied in his pragmatic theory of cognition and action.

In Mead's metaphysics, an act is to be understood as a fundamental unit of human experience (e.g. Mead 1938: 66). In fact, "wherever we find living forms, we find acts" (Mead 1927/1982: 108). Acts are, either reflective or unreflective, ways of being in the world of all living forms. In the life process, acts set up a space of the dialectics of means and ends in which living forms maintain and replicate themselves. Mead was convinced that the life processes in nature manifest what Clark calls adaptive coupling, which "occurs when a system (typically a plant or animal) evolves a mechanism that allows it to track the behavior of another system (a predator, or a source of food or energy)" (Clark 1999: 347). As Cornelis de Waal remarks, we can trace the processes of adaptive coupling from events as relatively simple as the sunflower turning towards the sun, up to very complex 
human behavior such as browsing the Internet (cf. Waal 2002: 19). What these, indeed very diverse, processes have in common, though, is their teleological nature - they are aimed (although mostly unreflectively) at achieving goals in the life-process: "All acts, as such, are teleological. They move towards a result which is a success or a failure" (Mead n.d./2011: 21). ${ }^{20}$ Goal-directed behavior (teleology of the act) is, thus, according to Mead the basic characteristic of all living forms (e.g. Mead 1938: 640). Mead would, thus, undeniably agree with contemporary findings of the philosopher of cognitive science, Radu J. Bogdan, who holds that goal-directedness should be viewed not only as a successful life-strategy, but in fact as one of the very conditions for survival and replication of all living forms (cf. Bogdan 1994: 19). ${ }^{21}$

As indicated above, Mead's theory of the act unfolds within the conceptual scheme delineated by the stage of impulse on the one end, and that of consummation on the other. Each act begins at the stage of an impulse which is defined by Mead as "a congenital tendency to respond in a specific manner to a certain sort of stimulus, under certain organic conditions" (Mead 1934/1967: 337). By contrast, an act finds its completion in consummation which can be characterized as a successful finishing or satisfaction of the particular course of action (cf. Mead 1938: 36). As indicated above, the impulse already contains, in itself, its goal (end-in-view) that would, thus, under ideal environmental conditions, lead the organism directly to the stage of consummation. In the case of higher-order organisms, however, this situation almost never takes place. This is why Mead introduces into his analysis of action two mediatory phases of the act, namely - perception and manipulation. The very occurrence of an impulse, Mead holds, indicates increasing lack of adjustment between an organism and its environment that urges the organism to employ a series of adaptive strategies (change of spatial position, movement, active searching for stimuli, etc.) that help it successfully achieve its goals. The lack of adjustment between an organism and its environment is therefore surmounted by means of mediatory phases of the act. The teleological character of the impulse sensitizes the organism to certain kinds of stimuli:

The process of sensing is itself an activity. In the case of vision this is most evidently the case. Here the movement of the eyes, the focusing of the lens, and the adjustment of the lines of vision of the two eyes require a complicated activity which is further complicated by the movements of the eyes which will bring the rays of light coming from all parts of the object upon the center of clearest vision. (Mead 1938: 3-4)

In the phase of perception the organism, with reference to its goals, actively brings into focus the appropriate characteristics of the environment. Arguing against Russell, Mead holds that perception (with vision being its paradigmatic example) is nothing like a camera which only passively receives "the data" from its environment (cf. Mead 1938: 133). There is nothing like the given, which is to say that the content of perceptual experience is not only goal-relative but also deeply movement-dependent: "The sensing of the object as so located that the organism takes a definite attitude toward it, involving possible movement toward or away from the object, is thus a part of the process of perception" (Mead 1938: 4). Nowadays, almost exactly the same point is made by Noë when he says: "The basis of perception, on our enactive, sensori-motor approach, is implicit practical knowledge of the ways movement gives rise to stimulation" (Noë 2004: 8). In other words, in the process of perception the organism has to perform certain practical strategies if it wants to bring the perceptual object into an appropriate focus. The very phase of perception bears with it, therefore, an important normative dimension. 
In the process of perception, the organism understands (however unreflectively) what it is supposed to do, if it wants to reach a distant object in a particular way..$^{22}$ At that point, however, we can see that the traditional line between perception and thinking could be put into question. It might no longer be true that thinking is an entirely inner activity based on the computational processes occurring inside our skulls. By contrast, in the pragmatic view, it is the implicit practical understanding of changes in the perceptual field on the basis of bodily movement that could possibly be regarded as the origin of thinking. It should also be noted that in this enactive paradigm it is the world itself on which the animal relies. The organism does not have to create some inner representations of the worldly structures if it is sufficient for it just to create appropriate ways of interaction with them in terms of bodily movements. ${ }^{23}$

At the stage of perception, Mead distinguished between what he called contact and distant experience: "The human animal is sensitive with five channels for experience; but all of these reduce to distance experience and contact experience" (Mead 1927/1982: 107). Contact experience is the immediate presence of the environment as it appears in unmediated physical opposition. By contrast, distance experience is the kind of experience we have of objects which are not within our reach. In opposition to the vast majority of the epistemological tradition, for Mead contact experience is more basic: "Reality reduces to possible future experiences" (Mead 1927/1982: 118). As de Waal eloquently puts it: "True to his pragmatism, Mead maintained that the meaning of a distance experience is the future contact experiences it represents" (Waal 2002: 21-22). Again, we arrive here at the notion of affordance - according to Mead a distant object in our experience is completely laid out in terms of possible actions we can carry out toward it: "The object in perception is a distant object. It invites us to action with reference to it, and that action leads to results which generally accomplish the act as a biological undertaking" (Mead 1938: 12). ${ }^{24}$ In Mead's view, the objects invite us to get into tactile contact with them, to manipulate and transform them, which is why Miller has called him a "haptic philosopher" (Miller in Mead 1982: 12). Alva Noë has recently made a similar point when he states that all perception is touch-like (cf. Noë 2004: 1). For Mead the ultimate test of experience lies in haptic contact, within which the validity of distant perceptual experience is examined..$^{25}$ Perception, involving movement towards a distant object, and leading ultimately to the consummatory stage of the act, applies, in Mead's view, to all animals.

With humans, however, Mead distinguishes another functional stage of action, namely the stage of manipulation. In the case human beings, the distance experience is connected to the contact experience by means of eye-hand coordination. The phase of manipulation, therefore, intervenes between perception of distant objects and successful completion of the act at the stage of consummation. For Mead, the role of the hand in the development of human intelligence is of crucial importance. Manipulation can be defined as human activity of transformation and exploitation of the environmental structures in order to achieve particular goals of action. The human animal, as Mead would call our species, does not proceed from the stage of perception directly to consummation but due to the high development of the hand, with its opposition of the thumb, is capable of delaying her response to environmental stimuli: "the process of exercising intelligence is the process of delaying, organizing and selecting a response or reaction to the stimuli of the given environmental situation" (Mead 1934/1967: 100). The existence and physiological structure of the hand enables human beings ${ }^{26}$ not to devour the desired 
object immediately but manipulate, reorganize or transform it in order to achieve further goals. In the opinion of Cornelis de Waal, the hand is, for Mead, in "many respects even more characteristic of human intelligence than the brain" (Waal 2002: 26). Humans are tool-using beings that use "implements that can extend the length or power of the hand" (Mead 1927/1982: 119). Mead suggests that by means of tools we can enlarge our bodyschema and use those tools as an actual extension of our limbs. As Rizzolatti and Sinigaglia have noted, the validity of this startling insight of Mead's has been recently confirmed by research conducted under the lead of Atsushi Iriki. What Iriki's team has, famously, found during their research of monkeys' brains is that those individuals that had been trained to use a rake when reaching for food exhibited enlarged cortical representations of the hand and arm. More specifically, the brain cells that are sensitive to both the look and the feel of the hand and arm treated the rake extension of the arm as if it were part of the body, that is - as if it were the arm itself (cf. Rizzolatti \& Sinigaglia 2008: 74-75). That is to say, the rake outright entered the monkey's body-schema and became temporarily a part of its body27. ${ }^{27}$ From the philosophical point of view, these findings suggest that the plasticity (especially) of human brains enables us, as Clark maintains:

To enter into deep and complex relationships with nonbiological constructs, props and aids [...] it is our special character, as human beings, to be forever driven to create, co-opt, annex and exploit nonbiological props and scaffoldings We have been designed by mother nature, to exploit deep neural plasticity in order to become one with our best and most reliable tools. (Clark 2003: 5)

By means of tool-usage, human beings actively manage their body-schema. Consequently, they also transform their peripersonal space, i. e. the space within our reach. ${ }^{28}$ What was merely present (distance experience) suddenly becomes available. "Where do we stop and where does the rest of the world begin?," asks Noë (2009: 80). In his opinion, there is no principled reason to think our bodies stop where we think they do. Similarly, Dewey once wrote: "The epidermis is only in the most superficial way an indication of where an organism ends and its environment begins" (LW 10: 64). The Chicago pragmatists, as well as the defenders of the extended mind theory, contend that technology increases our access to the world, which is to say that it increases the extent of what is, or at least can be, available for us. Our worlds are, therefore, not confined to what is memorized, perceived or "represented" inside our heads. We are creatures that, due to our mastery of technology, extend our minds ${ }^{29}$ and bodies outside our skinbags.

\section{Conclusion}

In the pragmatic view, we can therefore conclude, cognition is a way of close coupling between an organism and its environment. It is not something that happens exclusively in our heads. The world itself is immediately given to us due to our practical strategies of active engagement with the environmental structures. Thus, unlike classical empiricists, pragmatists maintain that the world does not come to us for free, it only shows up if we actively develop practical strategies of hooking up with it. In the version of pragmatism Dewey and Mead advocated, these practical strategies are encoded in our brains and bodies via attitudes and habits which attune us to particular worldly structures. Habits (executed in the form of so called deeds), then, as I was trying to argue, can be described as representations of these worldly structures if, by enacting them in our actions, we can accomplish our practical tasks. Successful employment of deeds in the world means that 
they are correct representations of the worldly structures they refer to since they stand the test of practical action. From this perspective it seems that pragmatism does not necessarily have to get rid of the notion of representation altogether. What it ought to do, on the other hand, is to reformulate it in terms of action. Representations, then, will cease to be defined in terms of pictures magically matching the outer world but will be situated where cognition unfolds, that is, in the world itself. If we adopt such a view, it is clear that, from the pragmatic perspective, we represent the world not so much in our heads but, much rather, through our bodies and embodied action in it.

The main contention of contemporary advocates of the extended mind theory saying that cognition is something which unfolds in the world (at least as much as in our heads) is not a new one. As I was trying to argue in this paper, Mead and Dewey held this position a century ago. However, this is not to mean that pragmatists cannot learn anything from the extended mind theory. Quite the contrary. Since pragmatism has always been a philosophical school aiming at conceptual clarity and "empirical responsibility" (Lakoff \& Johnson 1999: xi), it is through the prism of the extended mind theory that we pragmatists - can learn how to read our own classics in new and inspiring ways. Peirce once wrote: "modern philosophy has never been able quite to shake off the Cartesian idea of the mind, as something that 'resides' - such is the term - in the pineal gland. Everybody laughs at this nowadays, and yet everybody continues to think of mind in this same general way, as something within this person or that, belonging to him and correlative to the real world. A whole course of lectures would be required to expose this error" (CP 5.128). Today, we can see that Peirce was extremely optimistic about how long it would take to finally overcome Cartesianism. Even after decades of consistent opposition against it, the Cartesian picture of mind still holds captive a good portion of the contemporary philosophy of mind (mostly through various forms of internalism). That is why a firm alliance between pragmatism and the extended mind theory should be urgently pursued.

\section{BIBLIOGRAPHY}

ADAMS F., \& K. AIZAWA, (2001), “The Bounds of Cognition,” Philosophical Psychology, 14, 1, 43-64.

ADAMS F., \& K. AIZAWA, (2007/2010), The Bounds of Cognition, West Sussex, Wiley-Blackwell.

BARRETT L., (2011), Beyond the Brain: How Body and Environment Shape Animal and Human Minds, Princeton and Oxford, Princeton University Press.

BERNSTEIN R. J., (2010), The Pragmatic Turn, Malden (MA), Polity Press.

BOGDAN R., (1994), Grounds for Cognition: How Goal-guided Behavior Shapes the Mind, Mahwah (NJ), Lawrence Erlbaum Associates, Inc.

BROOKS R., (1991), “Intelligence without representation,” Artificial Intelligence, 47, 139-59.

CAMPBELL J., (1995), Understanding John Dewey. Nature and Cooperative Intelligence, Chicago \& La Salle (IL), Open Court. 
CLARK A., (1997a), Being There: Putting Brain, Body, and World Together Again, Cambridge (MA), The MIT Press.

CLARK A., (1997b), “The Dynamical Challenge,” Cognitive Science, 21, 4, 461-81.

CLARK A., (1999), “Embodied Cognitive Science?,” Trends in Cognitive Sciences, 3, 9, 345-351.

CLARK A., (2003), Natural-Born Cyborgs: Minds, Technologies, and the Future of Human Intelligence, Oxford, Oxford University Press.

CLARK A., (2008), Supersizing the Mind. Embodiment, Action and Cognitive Extension, Oxford, Oxford University Press.

DEWEY J., (1896), “The Reflex Arc Concept in Psychology,” The Early Works of J. Dewey, 1982-1898, vol. 5 (EW 5), ed. by J. A. Boydston, Carbondale, Southern Illinois University Press 1972, 96-110.

DEWEY J., (1934), Art as Experience, The Later Works of J. Dewey, 1934, vol. 10 (LW 10), ed. by J. A. Boydston, A. Caplan, Carbondale, Southern Illinois University Press 2008.

HANKInson R. J., (2003), “Academics and Pyrrhonists," in Ch. Shields (ed.), The Blackwell Guide to Ancient Philosophy, Oxford, Blackwell Publishing.

HURLEY S., (2008), “The Shared Circuits Model: How Control, Mirroring and Simulation Can Enable Imitation, Deliberation, and Mindreading," Behavioral and Brain Sciences, 31, 1, 1-22.

hUTTO D. D., \& E. MYIN, (2013), Radicalizing Enactivism. Basic Minds Without Content, Cambridge (MA), The MIT Press.

GIBSON J. J., (1979), The Ecological Approach to Visual Perception, Boston, Houghton-Mifflin.

IAcoBoni M., (2008), Mirroring People. The Science of Empathy and How We Connect with Others, New York (NY), Picador.

JAMES W., (1892/1984), Psychology: Briefer Course, Cambridge (MA), Harvard University Press.

JOAS H., (1985), G. H. Mead. A Contemporary Re-examination of his Thought, Cambridge (MA), The MIT Press.

JOAS H., (1997), “George Herbert Mead and the Renaissance of American Pragmatism in Social Theory," in C. Camic (ed.), Reclaiming the Sociological Classics: The State of the Scholarship, Oxford, Blackwell.

JoHnson M., (2007), The Meaning of the Body. Aesthetics of Human Understanding, Chicago \& London, University of Chicago Press.

KILPINEN E., (2008), "Pragmatism as a Philosophy of Action," Paper presented at the First Nordic Pragmatism Conference, Helsinki, Finland, June 2008.

KILPINEN E., (2011), "Social Theory," in S. Pihlström (ed.), The Continuum Companion to Pragmatism, London \& New York, Continuum, 139-49.

KOCZANOWICZ L., (1990), Analizy ludzkiego działania, Wrocław, Uniwersytet Wrocławski.

KRUEGER J., (2011), "Extended Cognition and the Space of Social Interaction," Consciousness and Cognition, 20, 3, 643-57.

LAKOFF G., \& M. JOHnSON, (1999), Philosophy in the Flesh. The Embodied Mind and Its Challenge to Western Thought, New York, Basic Books. 
LIZARDO O., (2007), “'Mirror Neurons,' Collective Objects and the Problem of Transmission: Reconsidering Stephen Turner's Critique of Practice Theory," Journal for the Theory of Social Behaviour, 37, 3, 319-50.

MADZIA R., (forthcoming), "Mead and Self-Embodiment: Imitation, Simulation and the Problem of Taking the Attitude of the Other," in Nungesser F., \& Ofner F. (eds.), Potentiale einer pragmatistischen Sozialtheorie. Beiträge anlässlich des 150. Geburtstags von George Herbert Mead, Wiesbaden, VS-Verlag, 2013.

MATURANA H. R., \& F. J. varela, (1980), "Autopoiesis and cognition: The realization of the living," Boston Studies in the Philosophy of Science, 42, Dordrecht, D. Reidel Publishing Company.

MEAD G. H., (1907), “Concerning Animal Perception,” Psychological Review, 14, 383-90.

MEAD G. H., (1910/1964), "What Social Objects Must Social Psychology Presuppose," in A. J. Reck (ed.), Selected Writings: George Herbert Mead, Chicago, University of Chicago Press.

MEAD G. H., (1926/1964), “The Nature of Aesthetic Experience," in A. J. Reck (ed.), Selected Writings: George Herbert Mead, Chicago, University of Chicago Press.

MEAD G. H., (1927/1964), “The Objective Reality of Perspectives,” in A. J. Reck (ed.), Selected Writings: George Herbert Mead, Chicago, University of Chicago Press.

MEAD G. H., (1927/1982), “1927 Lectures in Social Psychology,” in D. L. Miller (ed.), The Individual and the Social Self: Unpublished Work, Chicago, University of Chicago Press.

MEAD G. H., (1929/1964), “A Pragmatic Theory of Truth,” in A. J. Reck (ed.), Selected Writings: George Herbert Mead, Chicago, University of Chicago Press.

MEAD G. H., (1932), Philosophy of the Present, La Salle (IL), Open Court.

MEAD G. H., (1934/1967), Mind, Self, and Society: From the Standpoint of a Social Behaviorist, Chicago, University of Chicago Press.

MEAD G. H., (1938), Philosophy of the Act, Chicago, Chicago University Press.

MEAD G. H., (1982), The Individual and the Social Self: Unpublished Work, D. L. Miller (ed.), Chicago, University of Chicago Press.

MEAD G. H., (n.d./2011), "On the Self and Teleological Behavior," in F. C. Da Silva (ed.), G. H. Mead: A Reader, New York, Routledge.

MENARY R., (2007), Cognitive Integration. Mind and Cognition Unbounded, New York, Palgrave Macmillan.

MILLER D. L., (1973), “George Herbert Mead: Biographical Notes,” in W. R. Corti (ed.), The Philosophy of George Herbert Mead, Winthertur, Amriswiler Bücherei.

MILLER D. L., (1982), "Introduction," The Individual and the Social Self: Unpublished Work, D. L. Miller (ed.), Chicago, University of Chicago Press.

NOË A., (2004), Action in Perception, Cambridge (MA), The MIT Press.

NOË A., (2009), Out of our Heads: Why You Are Not Your Brain, and Other Lessons from the Biology of Consciousness, New York, Hill and Wang.

NOË A., (2012), Varieties of Presence, Cambridge (MA), Harvard University Press.

PEIRCE C. S., (1931-1958), Collected Papers of C. S. Peirce, 8 vols., ed. by C. Hartshorne, P. Weiss (vols. 1-6) and A. Burks (vols. 7-8), Harvard University Press, Cambridge (MA), 1931-1958 
QUÉRÉ L., (2011), “Towards a Social Externalism: Pragmatism and Ethnomethodology,” European Journal of Pragmatism and American Philosophy, 3, 2, 148-66.

Rizzolatti G., \& C. Sinigaglia, (2008), Mirrors in the Brain: How Our Minds Share Actions, Emotions, and Experience, Oxford, Oxford University Press.

ROCKWELL W. T., (2005), Neither Brain Nor Ghost. A Non-dualist Alternative to the Mind-Brain Identity Theory, Cambridge (MA), The MIT Press.

RoWLANDS M., (2003), Externalism. Putting Mind and World Back Together Again, Montreal/Kingston, McGill-Queen's University Press.

ROWLANDS M., (2006), Body Language: Representation in Action, Cambridge (MA), The MIT Press.

RUPERT R. D., (2009), Cognitive Systems and the Extended Mind, Oxford, Oxford University Press.

TURNER S., (2007), "Social Theory as a Cognitive Neuroscience," European Journal of Social Theory, $10,3,357-74$.

UEXKÜLL J., (1934/1957), “A Stroll Through the Worlds of Animals and Men: A Picture Book of Invisible Worlds," in C. H. Schiller (ed. et transl.), Instinctive Behavior: The Development of a Modern Concept, New York, International Universities Press, Inc.

VARELA F., THOMPSON E., \& E. ROSCH, (1991), The Embodied Mind: Cognitive Science and Human

Experience, Cambridge (MA), The MIT Press.

WAAL C., (2002), On Mead, Belmont (CA), Wadsworth.

WHEELER M., (2005), Reconstructing the Cognitive World. The Next Step, Cambridge (MA), The MIT Press.

\section{NOTES}

1. Although we are able to offer no historical evidence, Mead's profound interpreter and, at the same time, one of his best students - David L. Miller holds that this article of Dewey's must have been an outcome of mutual intellectual interchange between Dewey and Mead at the start of thei $r$ careers first in Ann Arbor and later in Chicago in 1890s (cf. Miller 1973: 32). Whether this is real ly the case is probably going to remain an open question. How- ever, as Joas shows, even Mead's c rucial early paper The Definition of the Psychical (1903) should be appreciated as a considerable ref inement of the ideas, presented in Dewey's criticism of the reflex arc concept (cf. Joas 1985: 69-89 ).

2. As James Campbell pointed out, Dewey's publication of this essay in Psychological Review shou ld be viewed from the broader context of Dewey's critical reception of the movement of so-called the 'New Psychology.' Cf. also Campbell (1995: 31-38).

3. Cf. also Clark (1997a: 163; 1997b: 476).

4. “...biological concepts are not merely causal but functional as well. Functions presuppose purp oses and goals. Dewey portrays experience as fundamentally purposive in opposition to the positi on that Dewey calls sensationalistic empiricism, which sees experience as discrete sense data that are intrinsically irrelevant to the goals of the perceiver. For Dewey there is no such thing as a $r$ aw feel; all experience is constituted by its relationship to the world and the goals of the experien cer" (Rockwell 2005: 88).

5. According to Kilpinen, by reversing the heuristic focus from what he calls "mind-first-explana tion of action" (characteristic of both the phenomenological as well as the analytic tradition) to e 
xplanation of how organic habits are established the philosophy of pragmatism brought about th e "Copernican revolution in conceptualization of action." Cf. Kilpinen (2008).

6. At present, this position is defended by thinkers like Alva Noë or Evan Thompson under the lab el of 'enac- tivism,' or 'actionism' (cf. Noë 2012), of which the pragmatist philosophers are early $p$ redecessors. Cf. esp. Noë (2004, 2009, 2012), Varela, et al. (1991).

7. Mead regarded Watsonian behaviorism as an incorrect theory that can be refuted on empirical grounds. Cf. Joas (1985: 113).

8. Mark Johnson, referring to the work of an Italian neuroscientist Vittorio Gallese arrives at a ve ry similar notion when he writes that a concept of an object is: "a model of structures of recurrin g organism-environment coupling, and it is a model for possible perceptions and actions that one might experience" (Johnson 2007: 159).

9. Mirror neurons are neurons that fire both when an animal acts and when the animal observes the same action performed by another. Thus, the neurons mirror the behavior of the other, as th ough the observer were itself acting. Such neurons have been directly observed in primate and o ther species including birds. In humans, brain activity consistent with that of mirror neurons has been found in the premotor cortex, the supplementary motor area, the primary somatosensory c ortex and the inferior parietal cortex (cf. Rizzolatti \& Sinigaglia 2008; Iacoboni 2008).

10. The discovery of mirror neurons also has profound implications for contemporary assessmen $t$ of Mead's views on social cognition as the recent research seems to suggest that there is an imit ation taking place at a fundamental level of social conduct (e.g. Iacoboni 2008). If this is really the case, some authors conclude that Mead's views on the nature of imitation and origins of selfhood (as included for instance in Mead (1934/1967: 51-61)) are essentially mistaken (cf. Turner 2007, fo $\mathrm{r}$ a reaction to his views, for instance, Lizardo 2007). While I do think that the discovery of mirror neurons implies a need to redefine the pragmatic treatment of imitation, I disagree with Turner $\mathrm{i}$ $\mathrm{n}$ his view that just because there are some imitative processes involved in human social cognitio $\mathrm{n}$, we should altogether discard the idea that the self is the product of social interaction. The imit ation taking place due to mirror neurons is taking place at sub-personal, pre-reflective level of co nsciousness and thus cannot, by itself, un- dermine the classical notion of the self as a product of reflective social interaction with which Mead was con- cerned the most. In the present article, ho wever, I will have to leave these questions aside as my primary goal here (which is the analysis of the pragmatic views on the nature of cognitive processes as such) and the space limita tions do $n$ ot allow me to deal with these questions in the depth they undoubtedly deserve. For a detailed tr eatment of this topic see Madzia (forthcoming).

11. In this regard, Rizzolatti \& Sinigaglia talk about the subset of mirror neurons which they have called "canonical neurons" (cf. Rizzolatti \& Sinigaglia 2008: 79-80). Canonical neurons reflect a ffordances, they fire when an animal perceives an object that affords certain kind of action.

12. Johnson describes them in terms of activation patterns and synaptic weights (cf. Johnson 20 07: 157-160).

13. 13 In this article, I propose to interpret habits as embodied manifestations or performances o $\mathrm{f}$ attitudes. Although Mead himself does not make such a distinction, it certainly does not contra dict his theory. Cf. Mead (1934/1967: 8-13, 125-134), Quéré (2011: 153-154).

14. Cf. Rowlands (2006: 93-111).

15. With a little bit of exaggeration we can say that without habits we would not be able to make i $t$ through the day. If we would be forced, on a daily basis, to figure out the most basic traits of our everyday lives over and over again, our intellectual capacities would soon surely break down.

16. A pragmatic account of representation through action might probably do just fine without th e informational condition altogether. The reason for this is primarily because it is not very clear what the term "information" means in this particular context. As Hutto and Myin argue, a truly $n$ aturalistic picture of cognition should abandon the idea that cognition is primarily contentful an $\mathrm{d}$ intentional. In this respect, cognition should not be taken primarily as "informational content 
processing" but rather as a process of adjustment of a living organism to its environment. In that respect, Hutto and Myin propose that the notion of information could (and should) be replaced $b$ y covariance (cf. esp. Hutto \& Myin 2013: 63-71). Indeed, Hutto and Myin's concept of covariance i $\mathrm{s}$, from the pragmatist perspective, much better suited for the talk of cognition than "informatio n."

17. It also makes a very good sense to say that if we want to effectively cope with the world, our a ctions should be led by rules of some specific kind. Within the realm of the extended mind theory , however, the norma- tive dimension of embodied action is still quite an underdeveloped project . A promising outline of how the extended mind theory might proceed along these lines was prop osed, for instance, by Menary (2007).

18. Representations defined in terms of deeds are, in this sense, also universal. Deeds embody ha bits, and one habit can be used to respond to multiple particular environmental situations (say, the skill to hit the switch of the light - by the same habit we can switch lights on in many places). Miller calls them "open" because, he says, "we do not know in advance the detailed character of particulars to which they may apply" (Miller 1973: 99). Since deeds are instances of habits, they, i $\mathrm{n}$ a sense, transcend environmental particulars to which they respond, they are action-universal s.

19. In Mead, we can find reference to something that might be called cognitive niche as well: "A s ocial organism - that is, a social group of individual organisms - constitutes or creates its own sp ecial environment of objects just as, and in the same sense as, an individual organism constitutes or creates its own special environment of objects (which, however, is much more rudimentary th an the environment constructed by a social organism)" (Mead 1934/1967: 130).

20. For a similar point, cf. Mead (1910/1964: 105-06).

21. According to Bogdan, the teleological adaptation could be almost identified with life itself (B ogdan 1994: 28-38).

22. This characteristic of animal perception is clearly visible for instance during their hunting for prey.

23. In Mead, we can see exactly this point in his explanation of the paradox of duality of perceptual content. Cf. Mead (1938: 240-51).

24. In the same manner Rizzolatti and Sinigaglia call perceptual objects "action proposals." Cf. Rizzolatti \&Sinigaglia (2008: 35).

25. In this respect, Mead interestingly comes close to ancient Stoics who, in their discussion with the skepticism of the middle Academia (Arcesilaus), introduced the notion of the graspable prese ntation (katalēptikē phantasia). Cf. Hankinson (2003: 271-73).

26. Mead was aware of the fact that similar situation applies for instance to apes as well. Cf. Mead (1938: 136-37).

27. Cf. also Noë (2009: 79-80).

28. As opposed to the so called 'extrapersonal space,' that is, the space out of our immediate reac h.

29. Would it not, however, suffice to say that our use of those tools is merely instrumental and th at all the "real" cognitive processing takes place solely inside our heads? This criticism is undeni ably a legitimate one and the discussion over it is still in progress - so far, with no clear winners. However, as Clark (1997a, 2003, 2008) illustrates through a vast number of practical examples, th e evidence that practical action on certain environmental structures and tools in some cases reall y constitutes cognitive processing is overwhelming. The cognitive architec- ture that humans are inclined to construct seems not only to complement and enhance our 'inner' cognitive processin $\mathrm{g}$ but also, if it were to be removed, then some of our cognitive competences would be either dimi nished to the minimum or would even never develop (Krueger 2011: 646). For the criticism of the views presented by Clark, cf. Adams \& Aizawa (2001, 2007/2010), Rupert (2009). 


\section{ABSTRACTS}

The goal of this paper is twofold. First, it examines the pragmatic ramifications of recent research in certain areas of cognitive science (embodied mind theory, extended mind theory). Second, it shows how the Chicago pragmatists (George H. Mead, John Dewey) not only envisioned these findings but also how, within certain strains of cognitive science, their work is explicitly appreciated for important preliminary insights which help us interpret the outcomes of current research. The argumentative line of the paper revolves around Mead's and Dewey's treatment of the relation between perception and action. Cognition, in the view of the Chicago pragmatists, is not divisible into atomistic, ontologically disconnected units but rather should be seen as an organic circuit within which stimuli and responses are mutually interdependent phases of an ongoing goal-directed active involvement of the organism in the environmental structures. According to Mead and Dewey, as well as the presently burgeoning branch of cognitive science called the "extended mind theory," cognition is not something that takes place exclusively in our heads but should be rather seen as an objective relation between organism and the environment. On the background of Mead's theory of the act (with its four stages - impulse, perception, manipulation, and consummation) the author points to certain surprising similarities between the pragmatists' treatment of the notion of cognition and ideas recently suggested by defenders of the extended mind theory.

\section{AUTHOR}

\section{ROMAN MADZIA}

Masaryk University, Department of Philosophy roman.madzia[at]mail.muni.cz 